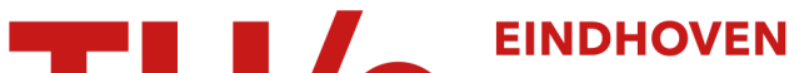 UNIVERSITY OF TECHNOLOGY
}

\section{Carbon nanotubes : from molecular to macroscopic sensors}

\section{Citation for published version (APA):}

Wood, J. R., Zhao, Q., Frogley, M. D., Meurs, E. R., Prins, A. D., Peijs, A. A. J. M., Dunstan, D. J., \& Wagner, H. D. (2000). Carbon nanotubes : from molecular to macroscopic sensors. Physical Review B, 62(11), 7571-7575. https://doi.org/10.1103/PhysRevB.62.7571

DOI:

10.1103/PhysRevB.62.7571

Document status and date:

Published: 01/01/2000

\section{Document Version:}

Publisher's PDF, also known as Version of Record (includes final page, issue and volume numbers)

\section{Please check the document version of this publication:}

- A submitted manuscript is the version of the article upon submission and before peer-review. There can be important differences between the submitted version and the official published version of record. People interested in the research are advised to contact the author for the final version of the publication, or visit the DOI to the publisher's website.

- The final author version and the galley proof are versions of the publication after peer review.

- The final published version features the final layout of the paper including the volume, issue and page numbers.

Link to publication

\section{General rights}

Copyright and moral rights for the publications made accessible in the public portal are retained by the authors and/or other copyright owners and it is a condition of accessing publications that users recognise and abide by the legal requirements associated with these rights.

- Users may download and print one copy of any publication from the public portal for the purpose of private study or research.

- You may not further distribute the material or use it for any profit-making activity or commercial gain

- You may freely distribute the URL identifying the publication in the public portal.

If the publication is distributed under the terms of Article $25 \mathrm{fa}$ of the Dutch Copyright Act, indicated by the "Taverne" license above, please follow below link for the End User Agreement:

www.tue.nl/taverne

Take down policy

If you believe that this document breaches copyright please contact us at:

openaccess@tue.nl

providing details and we will investigate your claim. 


\title{
Carbon nanotubes: From molecular to macroscopic sensors
}

\author{
Jonathan R. Wood, ${ }^{1}$ Qing Zhao, ${ }^{1}$ Mark D. Frogley, ${ }^{2}$ Erwin R. Meurs, ${ }^{1,3}$ Andrew D. Prins, ${ }^{2}$ Ton Peijs, ${ }^{4}$ David J. Dunstan, ${ }^{2}$ \\ and H. Daniel Wagner ${ }^{1}$ \\ ${ }^{1}$ Department of Materials and Interfaces, Weizmann Institute of Science, Rehovot 76100, Israel \\ ${ }^{2}$ Department of Physics, Queen Mary and Westfield College, University of London, London E1 4NS, United Kingdom \\ ${ }^{3}$ Department of Materials, Eindhoven University of Technology, Eindhoven, The Netherlands \\ ${ }^{4}$ Department of Materials Science and Engineering, Queen Mary and Westfield College, University of London, \\ London E1 4NS, United Kingdom \\ (Received 5 October 1999; revised manuscript received 23 March 2000)
}

\begin{abstract}
The components that contribute to Raman spectral shifts of single-wall carbon nanotubes (SWNT's) embedded in polymer systems have been identified. The temperature dependence of the Raman shift can be separated into the temperature dependence of the nanotubes, the cohesive energy density of the polymer, and the buildup of thermal strain. Discounting all components apart from the thermal strain from the Raman shift-temperature data, it is shown that the mechanical response of single-wall carbon nanotubes in tension and compression are identical. The stress-strain response of SWNT's can explain recent experimental data for carbon nanotube-composite systems.
\end{abstract}

\section{INTRODUCTION}

The Raman frequencies in a molecule depend on pressure or strain through the anharmonicity of the interatomic forces. The Raman signature of carbon nanotubes can be related to strain making them sensitive nanoscale dimensional strain gauges. ${ }^{1}$ This phenomenon has shown that hydrostatic pressures and molecular pressures derived from thermodynamic relations can be considered synonymous. ${ }^{2}$ Here we present relationships between shifts in the Raman spectrum induced by molecular pressure, macroscopic pressure, and temperature on single-wall carbon nanotubes as well as tensile test data for nanotube composites. Molecular pressure in a liquid can be defined in terms of the cohesive energy density which, like the surface energy or surface tension, describes the powerful cohesive forces that hold the liquid together. Values of the cohesive energy density (CED) can be calculated from experimental data on vaporization or on solubility, and have units of $\mathrm{J} \mathrm{cm}^{-3}$, or pressure (MPa). ${ }^{3}$

Molecular pressure was applied by immersing single-wall carbon nanotubes (Dynamic Enterprises, Ltd.) in a variety of liquids and dispersing them using ultrasound. The Raman spectrum was recorded using a Renishaw Raman microscope. To avoid interference from Raman signals due to the liquids, we focussed our attention on the disorder-induced $D^{*}$ Raman peak at $2610 \mathrm{~cm}^{-1}$ (in air), a spectral region relatively free of Raman peaks from the various liquids. Dispersed in liquids, the $D^{*}$ Raman peak shifts significantly from its position in air, as seen in Fig. 1(a) where the shift is plotted against the molecular pressure (CED) of the liquid. ${ }^{4}$ The data used to obtain the CED for each liquid are given in Table I. Figure 1(b) shows Raman spectral shifts for the nanotubes in three of the liquids with respect to the spectrum in air.

Macroscopic pressure was applied using a diamond-anvil cell. ${ }^{5}$ The nanotube sample consisted of a dry powder, together with a small piece of ruby, and liquid argon was loaded as the hydrostatic medium using the methods de- scribed in Ref. 6. Pressure was measured using the ruby fluorescence recorded with the Raman microscope. The cohesive energy density of argon is negligible, and therefore the positions of the $D^{*}$ Raman peak are plotted in Fig. 1(a) at the recorded hydrostatic pressures. Excellent agreement between these data points obtained with macroscopic pressure and the data obtained by immersion in liquids, both as regards the initial Raman shift with pressure and the pressure at which the intensity is quenched, confirms that the cohesive energy density can be regarded as a real pressure. This is further supported by comparing the quench pressures recorded by Ventkatswaren et $a l^{7}$ for lower wave number radial Raman modes. They used a methanol-ethanol pressure medium and noted that quenching occurred at $1500 \mathrm{MPa}$. This is strong evidence that their pressure dependence is shifted upwards by some $600-800 \mathrm{MPa}$ by the molecular pressure of the alcohol pressure medium adding directly to the macroscopic pressure of the diamond-anvil cell.

The cohesive energy density of a liquid depends on the temperature $(T)$. This dependence was measured by immersing the nanotubes in hexane at various temperatures. The solubility parameter is given by the semiempirical formula ${ }^{8}$

$$
\delta=m T+b
$$

and therefore,

$$
\mathrm{CED}=\delta^{2}=(m T+b)^{2} .
$$

For many hydrocarbons $m=-0.03 \mathrm{MPa}^{1 / 2} \mathrm{~K}^{-1}$ (Ref. 8) and for hexane ( $\delta=14.9 \mathrm{MPa}^{1 / 2}$ at $298 \mathrm{~K}$ ) $b=23.84 \mathrm{MPa}^{1 / 2}$. The nanotubes also have a small temperature dependence that can be represented by a linear function [Fig. 2(a)]. Figure 1 is used to determine the relationship between the Raman shift and cohesive energy density or pressure. Equations (1a) and (1b) are used to determine the cohesive energy density at each temperature. It is then possible to construct a correlation between the Raman shift and temperature. Figure 2(b) shows that this agrees very well with the measured shifts. 


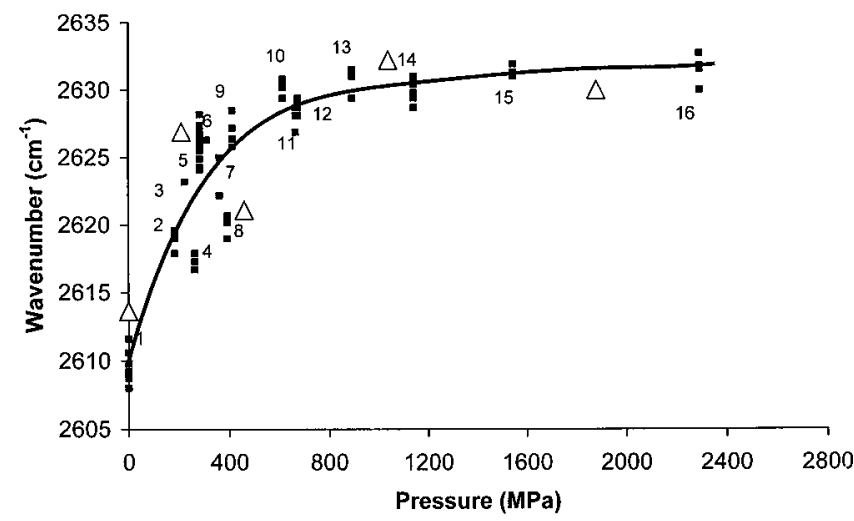

(a)

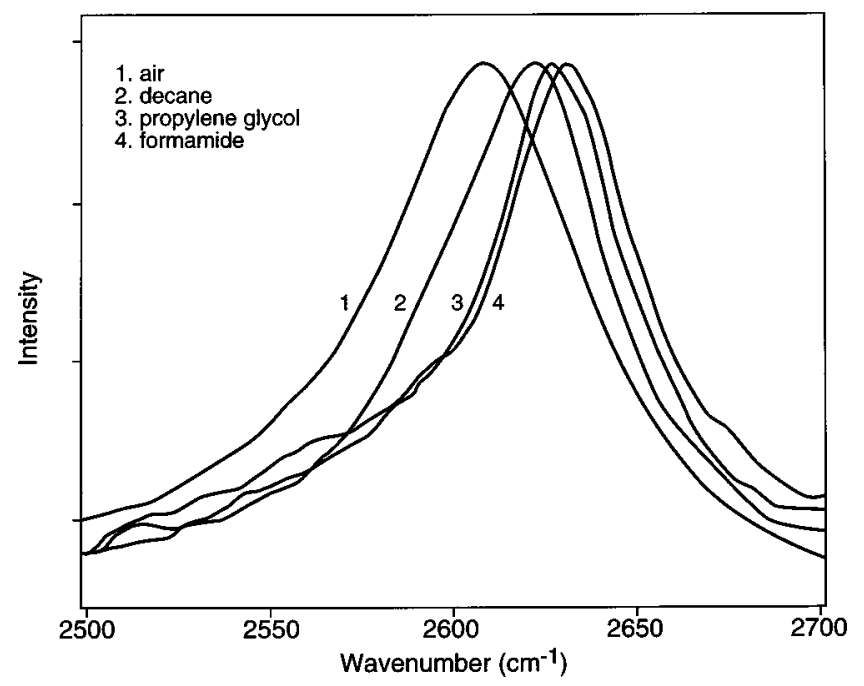

(b)

FIG. 1. (a) The peak positions of the $D^{*}$ Raman peak in singlewalled carbon nanotubes are plotted as a function of the molecular (by immersion in liquids, black square symbol) and macroscopic (using a diamond-anvil cell—or DAC-, open triangle symbol) pressure. The molecular pressure is the cohesive energy density (Table I) of the liquid in which the nanotubes were immersed: for these experiments the external applied pressure was ambient, $1 \mathrm{~atm}$. The macroscopic pressure was applied to nanotubes immersed in liquid argon as a hydrostatic pressure medium. At high pressure the intensity of the $D^{*}$ peak diminished in the DAC experiments and could not be measured above $2200 \mathrm{MPa}$. Similarly, the intensity of the $D^{*}$ peak in water was found to be lower. The solid line is a polynomial fit to the (liquid) data. The numbers correspond to the liquids in Table I. (b) Raman spectra for three of the liquids with respect to the position in air.

The nanotubes $(0.1 \mathrm{wt} \%)$ were embedded in an ultraviolet (UV) curable urethane acrylate polymer (Ebecryl 4858, Radcure). The nanotube/oligomer dispersion was spread onto glass with a doktor blade to induce flow orientation. The thin films were immediately cured by exposure to an UV source. At this low-nanotube concentration, tensile tests revealed that there was no significant improvement in the mechanical properties of the films with respect to the pure polymer.

The films were tested in two ways: (1) cured and uncured (the nanotube/oligomer dispersion) samples were cooled incrementally to liquid-nitrogen temperatures and Raman shifts were recorded at each temperature; (2) tensile specimens were prepared by cutting the films in the flow direction

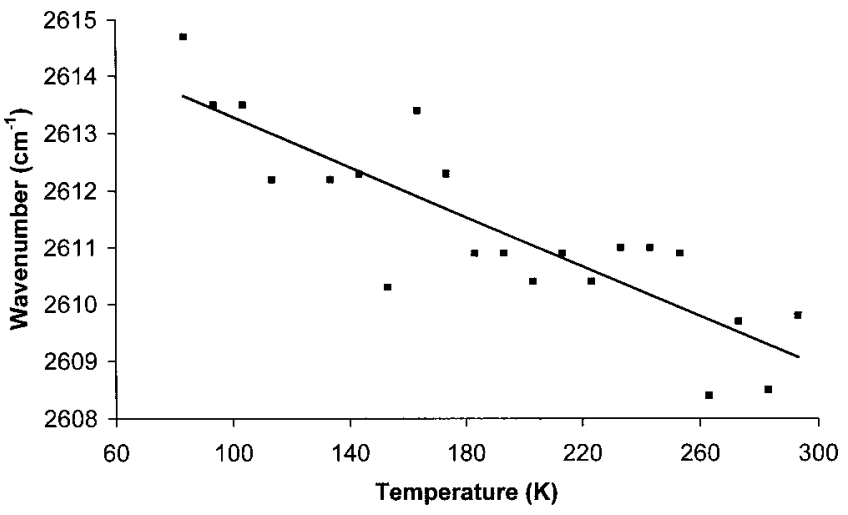

(a)

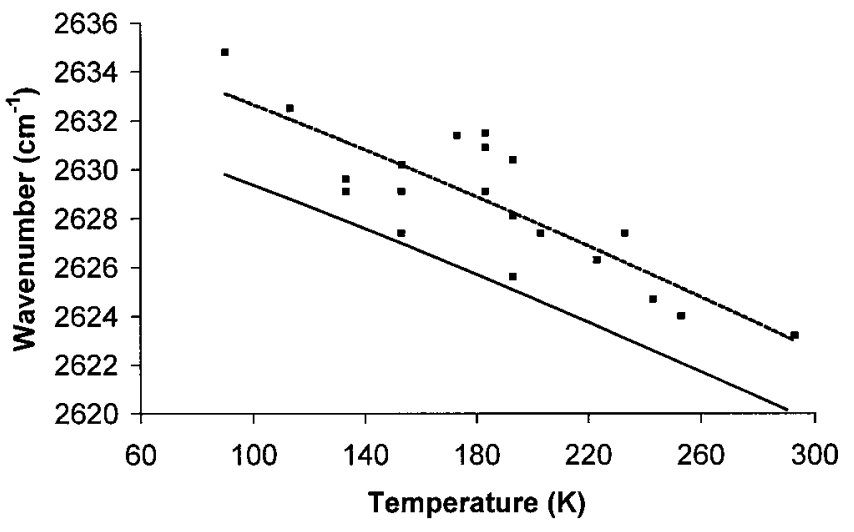

(b)

FIG. 2. (a) The temperature dependence of the Raman shift of single-wall carbon nanotubes in air, measured by placing the dry nanotubes in a temperature stage (a linear line adequately represents the data). (b) Temperature dependence of the $D^{*}$ Raman peak of single-wall carbon nanotubes in hexane. The dotted line is a quadratic fit to the data. The solid line is the construct of the semiempirical temperature dependence of the cohesive energy density of hexane [Eq. (1b)] and the temperature dependence of the nanotubes. The trends are similar, with difference in absolute values being dictated by the polynomial fit to the data in Fig. 1.

and perpendicular to the flow direction and tested in a minitensile testing machine with Raman shifts recorded incrementally with tensile strain.

Figure 3 shows the temperature dependence of the Raman signature for the cured and uncured composites. The difference can be explained in terms of the thermal strains that have built up in the solid (cured) polymer, which are subsequently transferred by shear from the contracting matrix to the nanotubes, as the composite is cooled below the glass transition temperature. The increase in the wave number with decreasing temperature for the uncured system can be explained by the temperature dependence of the cohesive energy density and the nanotubes themselves (a liquid cannot support a shear stress without flowing, thus negating the possibility of stress transfer by shear). The solid line is a simple quadratic fit to the data, while the dotted line has been calculated from the solubility parameter of the polymer and the semiempirical relationship between the cohesive energy density $\left(\delta^{2}\right)$ and the temperature [Eq. 1(b)], which is also a quadratic function. The solubility parameter $\delta$ of the polymer and the oligomer were calculated from Small's attraction 
TABLE I. Data for the calculation of the molecular pressures of the liquids and mean Raman shifts for the $D^{*}$ peak.

\begin{tabular}{|c|c|c|c|c|}
\hline & & $\begin{array}{c}\text { Solubility parameter } \\
\text { at } 298 \mathrm{~K}\left(10^{3} \mathrm{~J}^{1 / 2} \mathrm{~m}^{-3 / 2}\right)\end{array}$ & $\begin{array}{c}\text { Cohesive } \\
\text { energy } \\
\text { density } \\
(\mathrm{MPa})\end{array}$ & $\begin{array}{c}\text { Mean Raman } \\
\text { shift } \\
\left(\mathrm{cm}^{-1}\right)\end{array}$ \\
\hline 1 & air & 0 & 0 & 2610.1 \\
\hline 2 & decane & 13.5 & 182.3 & 2619.1 \\
\hline 3 & hexane & 14.9 & 222.0 & 2623.2 \\
\hline 4 & dodecane & 16.2 & 262.4 & 2617.4 \\
\hline 5 & cyclohexane & 16.8 & 282.2 & 2626.1 \\
\hline 6 & carbon tetrachloride & 17.6 & 309.8 & 2626.3 \\
\hline 7 & chloroform & 19.0 & 361.0 & 2623.6 \\
\hline 8 & hexylene glycol & 19.8 & 392.0 & 2620.3 \\
\hline 9 & acetone & 20.3 & 412.1 & 2627.0 \\
\hline 10 & diethylene glycol & 24.8 & 615.0 & 2630.3 \\
\hline 11 & propylene glycol & 25.8 & 665.6 & 2627.9 \\
\hline 12 & ethanol & 26.0 & 676.0 & 2628.9 \\
\hline 13 & ethylene glycol & 29.9 & 894.0 & 2630.7 \\
\hline 14 & glycerol & 33.8 & 1142.4 & 2630.2 \\
\hline 15 & formamide & 39.3 & 1544.5 & 2631.4 \\
\hline 16 & water & 47.9 & 2294.4 & 2631.7 \\
\hline
\end{tabular}

constants $^{9}$ to give a value of $23 \mathrm{MPa}^{1 / 2}$ at $298 \mathrm{~K}$ for both the cured and uncured system. This is in agreement with solubility parameter data for other urethane-based polymers. ${ }^{3}$ From the calculated cohesive energy density of the polymer, the initial Raman wave number of nanotubes in the polymer at $298 \mathrm{~K}$ can be determined from Fig. 1. The temperature dependence of the solubility parameter of hexane $(m=$ -0.03 ) was used for the polymer as the coefficient was unknown a priori, although literature values for polymer melts are similar to this value. ${ }^{10}$ The two lines coincide exactly at the glass transition temperature of the polymer $(363 \mathrm{~K})$, the temperature at which the thermal stresses are negligible. Subtraction of the dotted line of the uncured system from the data of the cured system yields the contribution of the thermal strain. ${ }^{11}$ Figure 4 shows the relation between thermal strain and Raman wave number shift for two polymer systems, polyurethane acrylate and polycarbonate, a thermoset and thermoplastic, respectively. Table II gives the relevant material parameters. The relationship is almost linear, supporting the strain identical assumption, and describes the Raman response of the nanotubes with compressive strain.

Figures 5(a) and 5(b) show the Raman shift with axial tensile strain for the longitudinal and transverse samples, re- spectively. The difference between the two graphs implies that a reasonable degree of orientation has been obtained from the sample preparation procedure. The solid line in Fig. 5 (a) is simply the negative of the slope in Fig. 4 clearly showing that the Raman shift with tensile strain and compressive strain are identical once the temperature-dependent parameters have been subtracted from the latter (Fig. 4), as described above. Another consequence of Figs. 5(a) and 5(b) is that the $D^{*}$ peak apparently responds primarily to strains along the length of the tubes. This allows us to assume tentatively that the $D^{*}$ peak, which has $A_{1 g}$ vibrational symmetry, is related to breathing modes along the nanotube axis. ${ }^{12}$

The mechanical response of the Raman shift in tension and compression implies that the Young's moduli in tension and compression are similar, at least over the strain range under investigation here. It is possible to construct the tensile stress-strain response of the nanotubes (Fig. 6). Figure 1 provides the relationship between the cohesive energy density or hydrostatic pressure and the Raman shift to determine the nanotube response with stress, while Fig. 4 or 5 (a) give the response with strain (the slopes are the same). Note that the absolute values of stress-strain response are different from those where the temperature dependence of the tubes

TABLE II. Mechanical and thermodynamic parameters for the two polymer systems.

\begin{tabular}{lcc}
\hline \hline Parameters & Polyurethane acrylate & Polycarbonate \\
\hline Young's modulus $E(\mathrm{MPa})$ & 1200 & 2200 \\
Poisson's ratio $\nu$ & 0.35 & 0.3 \\
Thermal expansion coefficient $\alpha\left(\mathrm{K}^{-1}\right)$ & $110 \times 10^{-6}$ & $65 \times 10^{-6}$ \\
Glass transition temperature $T_{g}(\mathrm{~K})$ & 363 & 423 \\
Solubility parameter at $\left.298 \mathrm{~K}^{1 / 2} \mathrm{MPa}\right)$ & 23 & 19.6 \\
Cohesive energy density at $298 \mathrm{~K}(\mathrm{MPa})$ & 529 & 385 \\
Density $\left(\mathrm{g} / \mathrm{cm}^{3}\right)$ & 1.14 & 1.2 \\
\hline \hline
\end{tabular}




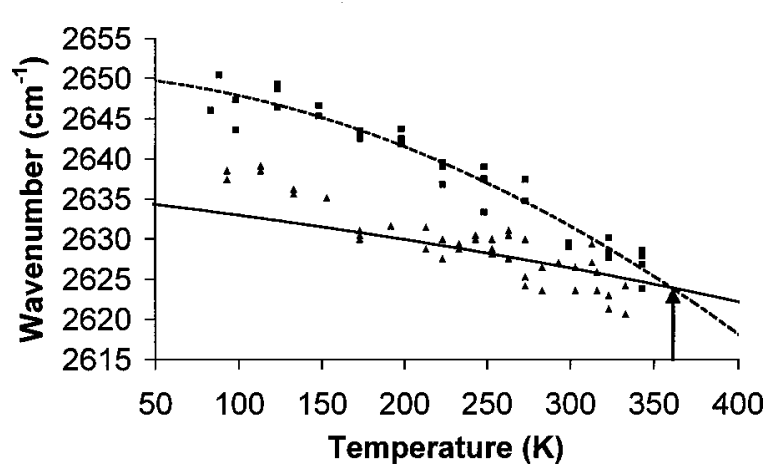

FIG. 3. Temperature dependence of the $D^{*}$ Raman peak of single-wall carbon nanotubes $(0.1 \mathrm{wt} \%)$ in an UV cured urethane acrylate polymer (squares) and the uncured oligomer (triangles). The dotted line is a quadratic fit to the data. The solid line is a construct of the semiempirical temperature dependence of the cohesive energy density of the polymer $\left(m=-0.03 \mathrm{MPa}^{1 / 2} \mathrm{~K}^{-1}\right)$ and the temperature dependence of the nanotubes. The intersection of the two lines coincides exactly with the $T_{g}$ of the polymer $(363 \mathrm{~K})$, the temperature where the thermal strain becomes negligible. The deviation of the oligomer data (triangles) from the broken line at progressively lower temperatures is possibly a consequence of compressive stresses being transferred from the polymer into the nanotubes at temperatures below the solidification temperature. Alternatively, the relation between the CED and temperature [Eq. (1b)] is not applicable over the full temperature range.

and the CED have not been included ${ }^{1,2}$ although the shape is similar. The modulus can be seen to be an increasing function of strain (Fig. 6) and is similar in form to other network structures such as elastomers. ${ }^{13}$ Interestingly, carbon fibers also exhibit upward curvature in the stress-strain response at high strains. ${ }^{14}$ A stress-strain curve for multiwall carbon nanotubes was recently obtained experimentally by $\mathrm{Yu}$ et al. ${ }^{15}$ but a direct comparison with the curve produced here

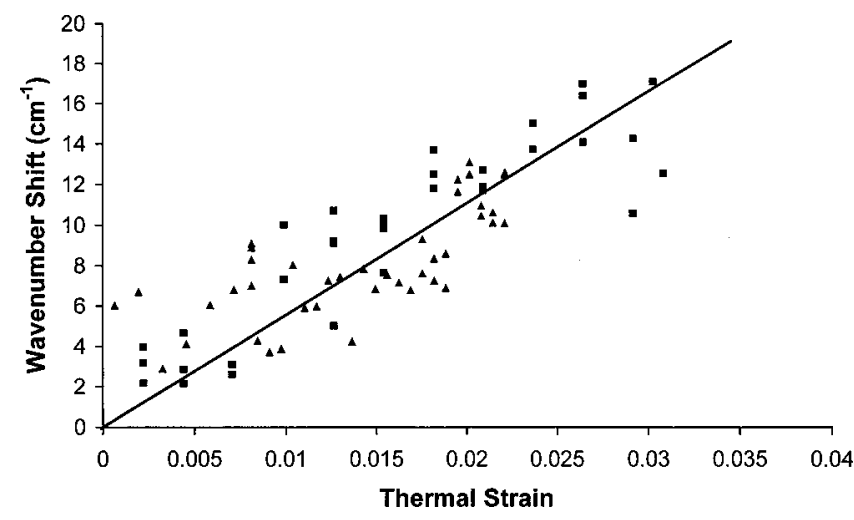

FIG. 4. Subtraction of solid polymer data from semiempirical construct in Fig. 3 yields the shift in the $D^{*}$ Raman peak of singlewall carbon nanotubes with the thermal strain transferred from the contracting matrix to the nanotubes. The squares are for the polyurethane acrylate system shown in Fig. 3 (thermoset), the triangles are for a polycarbonate matrix (thermoplastic). Note that the graph starts at zero, since the wave number of both the cured and uncured polymer in Fig. 3 were the same at the $T_{g}$. The increase in wave number with strain shows that the nanotubes are under compression. The linearity of the plot suggests that the strain identical assumption is applicable to the nanotube composite system.

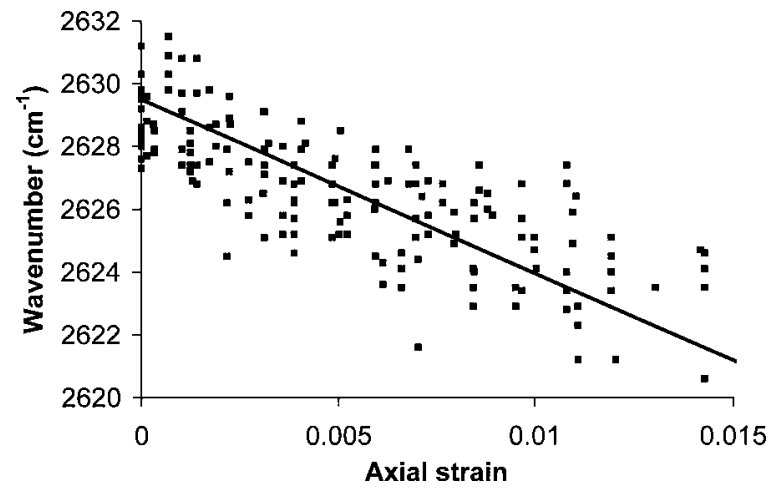

(a)

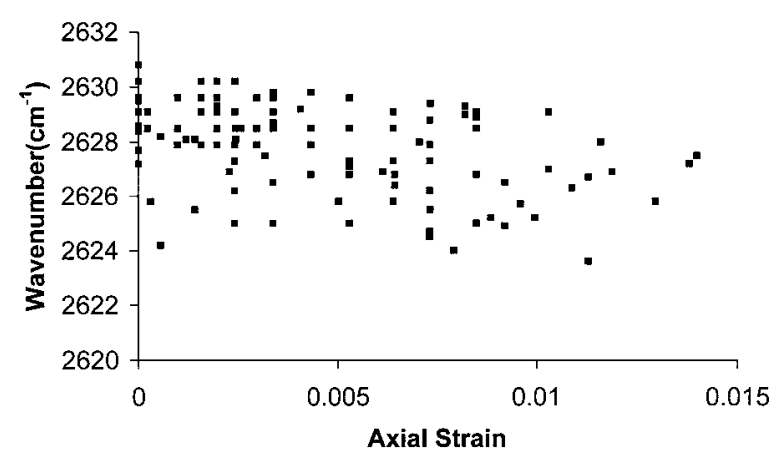

(b)

FIG. 5. (a) The strain response of the $D^{*}$ Raman peak of singlewall carbon nanotubes $(0.1 \mathrm{wt} \%)$ in an UV cured urethane acrylate polymer (the loading direction was parallel to the flow direction). The solid line is relationship between the Raman shift of the $D^{*}$ peak and strain from Fig. 4. The concordance between the tensile Raman shift data and the line determined from the thermal strain (compressive) data (Figs. 3 and 4), shows that the mechanical response of single-wall carbon nanotubes in tension and compression are the same. (b) The strain response of the transverse samples showing significant differences to the longitudinal samples.

may be misleading since the present paper deals with singlewall nanotubes. The data presented in Ref. 15 is somewhat noisy but it is interesting to note that one of the tubes tested by Yu et al. (specimen No. 2 in Fig. 2(b), Ref. 15) has a stress-strain curve that indeed is elastomerlike (and is not noisy), as seen in Fig. 7.

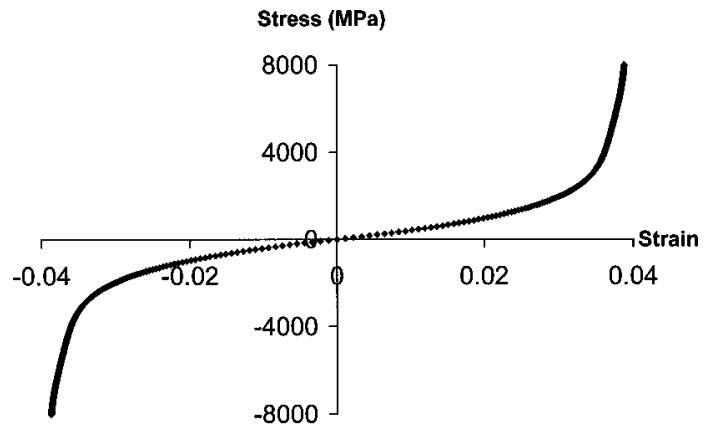

FIG. 6. Experimental stress-strain response of single-wall carbon nanotubes. The graph is a construct of the solid line in Fig. 4 or 5(a) (Raman shift with respect to strain) and the polynomial fit to the data in Fig. 1 (Raman shift with respect to hydrostatic pressure or cohesive energy density). The pressure data has been converted to stress in the nanotube by using the relation for a closed end cylinder $[\sigma=\operatorname{Pr} / 2 t$, where $t=0.066 \mathrm{~nm}$ Ref. 19 and $r=5.5 \mathrm{~nm}$ ]. 


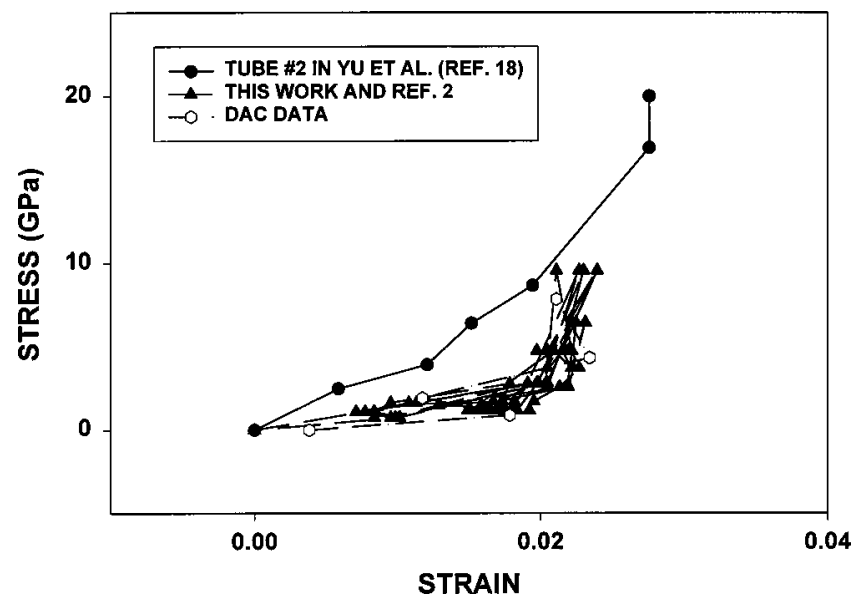

FIG. 7. A comparison between the experimental stress-strain curve of a specific multiwall carbon nanotube (tube No. 2 in $\mathrm{Yu}$ et al., Ref. 15) and the stress-strain curves obtained for single-wall carbon nanotubes in this and previous work (Ref. 2). Other multiwall nanotube specimens tested by Yu et al. (Ref. 15) had more noisy stress-strain curves.

The shape of the stress-strain curve is a potential reason for the low performance of nanotube reinforced composites, which have, so far, not shown the expected improvements in mechanical properties above that of the base polymer. Recent mechanical data using DMTA on nanotube reinforced composites $^{16}$ and on polymers reinforced with cellulose fibers ${ }^{17}$ both exhibit small improvements in the modulus below the glass transition temperature $T_{g}$ but large retention of modulus above the $T_{g}$ of the polymer matrix. The values of carbon nanotube moduli, determined by fitting DMTA data to short fiber composite models, ${ }^{16}$ are much lower than values attained by testing individual tubes. ${ }^{18}$ In view of the stress-strain curve presented here, we suggest that nanotubes have the potential to reinforce the matrix provided that higher mechanical strains are applied; possibly above the $T_{g}$.

\section{CONCLUSIONS}

We have presented the mechanical response of singlewall nanotube composites and have shown that strain induced Raman shifts in tension are identical to those in compression. Diamond-anvil cell experiments confirm that the cohesive energy density of the surrounding medium can be treated as a molecular hydrostatic pressure and the temperature dependence of the cohesive energy density adds further support to the fact that the nanotubes are sensing molecular strains. The shape of the constructed stress-strain curve (tension or compression) implies that single-wall nanotubes would be a potentially useful reinforcement for high-strain composite systems or for the retention of mechanical properties at high temperatures.

\section{ACKNOWLEDGMENTS}

This project was supported in part by a grant from the Minerva Foundation, and in part by the Israel Science Foundation founded by the Israel Academy of Sciences and $\mathrm{Hu}-$ manities. H.D.W. is the incumbent of the Livio Norzi Professorial Chair.
${ }^{1}$ J. R. Wood and H. D. Wagner, Appl. Phys. Lett. (to be published)

${ }^{2}$ J. R. Wood, M. D. Frogley, E. R. Meurs, A. D. Prins, T. Peijs, D. J. Dunstan, and H. D. Wagner, J. Phys. C 103, 10388 (1999).

${ }^{3}$ E. A. Grulke, Polymer Handbook, 3rd ed. edited by J. Brandrup and E. H. Immergut (Wiley, New York, 1989), pp. 519-559.

${ }^{4}$ The molecular pressure (CED) can be calculated from the energy of vaporization $\Delta E_{v}$ the enthalpy of vaporization $\Delta H_{v}$, and the solubility parameter $\delta$ using (Ref. 3) $\mathrm{CED}=\delta^{2}=\Delta E_{v} / V$ $\approx \Delta H_{v}-R T / V$, where $V$ is the molar volume of the liquid, $T$ is the temperature, and $R$ is the universal gas constant.

${ }^{5}$ D. J. Dunstan and W. Scherrer, Rev. Sci. Instrum. 59, 627 (1988).

${ }^{6}$ I. L. Spain and D. J. Dunstan, J. Phys. C 22, 923 (1989).

${ }^{7}$ U. D. Venkateswaran, A. M. Rao, E. Richter, M. Menon, A. Rinzler, R. E. Smalley, and P. C. Eklund, Phys. Rev. B 59, 10928 (1999).

${ }^{8}$ A. F. M. Barton, Handbook of Solubility Parameters and Other Cohesion Parameters (Boca Baton, 1983), Chap. 9.

${ }^{9}$ D. W. Van Krevelen, Properties of Polymers, 3rd ed. (Elsevier Science, Amsterdam, 1990), pp. 189-226.

${ }^{10}$ A. F. M. Barton, Ref. 8, Chap. 14.

${ }^{11}$ Assuming that the thermal strain in the nanotube is equal to the thermal strain in the cured polymer and that the thermal expansion coefficient of the polymer matrix $\alpha_{m}$ is much greater than that of the carbon nanotube $\alpha_{\mathrm{NT}}$, it is possible to construct a relation between the thermal strain and the Raman shift, using $\varepsilon=\left(\alpha_{m}-\alpha_{\mathrm{NT}}\right) \Delta T \approx \alpha_{m} \Delta T$, where $\Delta T$ is the difference in temperature between the glass transition temperature (no thermal stress) and the ambient temperature.

${ }^{12}$ R. Saito, T. Takeya, T. Kimura, G. Dresselhaus, and M. S. Dresselhaus, Phys. Rev. B 59, 2388 (1999).

${ }^{13}$ L. R. G. Treloar, The Physics of Rubber Elasticity, 3rd ed. (Oxford University Press, Oxford, 1975), pp. 80-90.

${ }^{14}$ G. Dorey, J. Phys. D 20, 245 (1987).

${ }^{15}$ M.-F. Yu, O. Lourie, M. J. Dyer, K. Moloni, T. F. Kelly, and R. S. Ruoff, Science 28, 287 (2000).

${ }^{16}$ M. S. P. Shaffer and A. H. Windle, Adv. Mater. 11, 937 (1999).

${ }^{17}$ L. Chazeau and J. Y. Cavaille, Proceedings of the 12th International Conference on Composite Materials, Paris, 1999.

${ }^{18}$ A. Krishnan, E. Dujardin, T. W. Ebbesen, P. N. Yianilos, and M. M. J. Treacy, Phys. Rev. B 58, 14013 (1998).

${ }^{19}$ B. I. Yakobson, C. J. Brabec, and J. Bernholc, Phys. Rev. Lett. 76, 2511 (1996). 